\title{
RELAÇÕES ENTRE CISALHAMENTO, MAGMATISMO E ANATEXIA: EXEMPLO DA ZONA DE CISALHAMENTO CRUZEIRO DO NORDESTE, PROVÍNCIA BORBOREMA, BRASIL
}

\author{
Salviano Pereira da Silva ${ }^{1}$ \\ Andres Bustamante ${ }^{2}$
}

\author{
10.18190/1980-8208/estudosgeologicos.v31n1p27-43 \\ ${ }^{1}$ Programa de Pós Graduação em Geociências-PPGEOC, Universidade Federal de \\ Pernambuco-UFPE, Av. da Arquitetura, s/n, CEP 507740-550. \\ E-mail: salviano pereira@hotmail.com \\ ${ }^{2}$ Departamento de Geologia, Universidade Federal de Pernambuco-UFPE, Av. da \\ Arquitetura, s/n, CEP 507740-550. E-mail: andres.bustamente@ufpe.br
}

\begin{abstract}
RESUMO
A extensa trama de zonas de cisalhamento presentes ao longo da Província Borborema, nordeste do Brasil, faz desta região um dos locais ideais para estudar processos crustais que envolvem a formação dessas estruturas, em especial sua relação com corpos magmáticos. As relações de campo, análise microtectônica e modelamento termodinâmico de gnaisses migmatíticos próximos à Zona de Cisalhamento Cruzeiro do Nordeste, no limite entre os Terrenos Rio Capibaribe e Alto Moxotó, mostram que a evolução tectono-termal apresenta relação direta com o alojamento de corpos ígneos alinhados segundo a zona de cisalhamento. A evolução da região inicia-se por um processo de encurtamento crustal associado a um transporte tectônico para NW. Há um notável aumento da temperatura para norte, que culmina no início da anatexia em cerca de $\sim 650^{\circ} \mathrm{C}$ e $\sim 0.9 \mathrm{GPa}$. A transição para o regime transcorrente resultou do escape tectônico facilitado pelo enfraquecimento reológico da crosta devido a presença de bolsões de melt associado a uma leve descompressão em aproximadamente $750^{\circ} \mathrm{C}$ e $0.7 \mathrm{GPa}$.
\end{abstract}

Palavras-chave: Província Borborema, zonas de cisalhamento, migmatitos, magmatismo

\begin{abstract}
The Borborema Province, northeastern Brazil, exhibit an extensive framework of shear zones in spatial proximity with syn-tectonic magmatism that makes it a perfect place to understand their relationship. In the eastern portion of this province an important dextral shear zone, that divides into two terranes, was originated during an escape tectonics after an oblique collision after a tectonic transport to NW. The recrystallization of quartz and feldspar shows a remarkable increase towards the shear zone, interpreted as a temperature increase during deformation. Thermodynamic modelling coupled with field relationship shows that high strain migmatitic textures such as stromatic structure was formed at $\sim 650{ }^{\circ} \mathrm{C}$ and $\sim 0.9 \mathrm{GPa}$ prior to the shear development. Whereas low strain migmatites with schollen texture was formed at $\sim 750$ ${ }^{\circ} \mathrm{C}$ and $\sim 0.7 \mathrm{GPa}$. We propose that the presence of melt during an oblique collision facilitated the emplacement of shear structures due to a thermal anomaly during the emplacement of syn-tectonic plutons.
\end{abstract}

Keywords: Borborema Province; shear zones; migmatites; magmatism 


\section{INTRODUÇÃO}

$\begin{array}{lllr}\text { O estudo } & \text { de zonas } & \text { de } \\ \text { cisalhamento é importante } & \text { para } \\ \text { compreender a } & \text { evolução } & \text { da }\end{array}$ deformação nos processos crustais. Durante processos deformacionais dúcteis, a temperatura associada é um dos principais fatores que influenciam o desenvolvimento da trama resultante (e.g., Passchier \& Trouw, 2005). Sua influência parte de estudos experimentais (e.g., Hirth \& Tullis, 2002) que sugerem uma relação entre regimes deformacionais com temperatura.

Diversos autores questionam a dominância da temperatura durante processos deformacionais. Argumentase que fatores como tamanho dos cristais, diversidade mineralógica e a presença de níveis micáceos podem influenciar mais do que a temperatura (e.g., Platt \& Behr, 2011; Hunter et al., 2016, 2019).

A trama de zonas de cisalhamento com mais de $200 \mathrm{~km}^{2}$ de extensão (Vauchez et al., 1995) associadas ao intenso magmatismo, tornam a Província Borborema um local ideal para estudar a relação entre formação de zonas de cisalhamento e magmatismo. Nesta província observase relações entre essas estruturas com o intenso plutonismo sin-tectônico o que motivou a investigação por diversos trabalhos (e.g., Archanjo et al., 2008; Miranda et al., 2020; Neves et al., 1995, 2000; Weinberg et al., 2004). Contudo, a possível influência de eventos de anatexia não são corriqueiramente considerados.

Nesta contribuição são usadas análises qualitativas de microtectônica e descrição detalhada de processos de fusão parcial registrada em migmatitos do embasamento representados pelo Complexo Pão de Açúcar, próximo à Zona de Cisalhamento Cruzeiro do Nordeste (Fig. 1), com o intuito de sugerir relações entre a história termal da zona de cisalhamento, eventos de anatexia e o magmatismo associado.

\section{MÉTODOS}

Foram coletadas 38 amostras e selecionadas 26 para análise micropetrográfica. A classificação das estruturas e texturas de migmatização segue a proposta de Sawyer (2008).

Seguindo a proposta de Passchier \& Trouw (2005) foi realizada a análise microtectônica em 4 amostras para qualificação da temperatura em que ocorreram os processos deformacionais. Essas amostras foram escolhidas de acordo com a distância à zona de cisalhamento, i.e., das porções pouco até as mais influenciadas pelo cisalhamento.

Para investigar o processo de migmatização no Complexo Pão de Açúcar foi realizada a modelagem termodinâmica de uma amostra de mesossoma (Accioly et al., 2015). Para tal, o programa Theriak-Domino (versão 11.03.2020; de Capitani \& Brown, 1987) foi utilizado em conjunto com a base termodinâmica de Holland \& Powell (2011). O sistema escolhido foi o C-NCKASH com $\mathrm{CO}_{2}$ e água em excesso na proporção 1:4, considerando uma rocha de composição quartzo-feldspática, com o objetivo de investigar a fusão parcial. A quantidade da fase fluida inferida foi obtida a partir das perdas por ignição (LOI). 

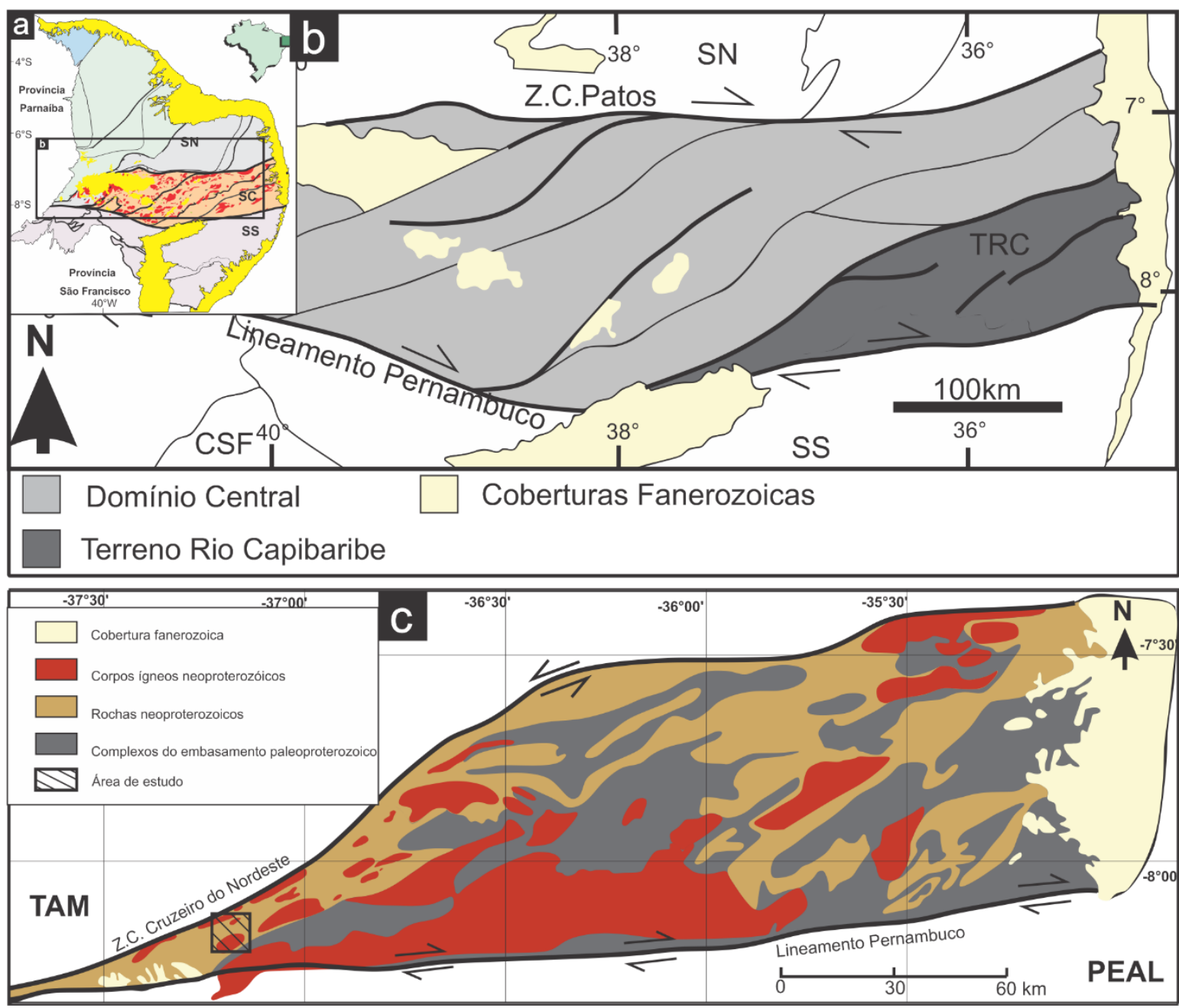

Figura 1: (a) Esboço simplificado da Província Borborema com destaque para a localização do Domínio Central; (b) Esboço do Domínio Central (cinza claro); destacado em cinza escuro encontra-se o Terreno Rio Capibaribe; (c) Mapa geológico simplificado do Terreno Rio Capibaribe destacando a localização da área de estudo; (a-b modificados de Van Schmus et al., 2011; c modificado de Brito Neves et al., 2013).

\section{CONTEXTO GEOLÓGICO}

A extensa trama de zonas de cisalhamento da Província Borborema, notadamente as zonas de cisalhamento Patos e Pernambuco com trend E-W, são os principais marcadores de subdivisão em Domínios Norte, Central e Sul (Fig. 1; Neves et al., 2015, e referências inclusas).
A área de estudo localiza-se no Terreno Rio Capibaribe, porção leste do Domínio Central, próximo a Zona de Cisalhamento Cruzeiro do Nordeste, limite proposto entre os Terrenos Rio Capibaribe e Alto Moxotó (Fig. 1, 2). 


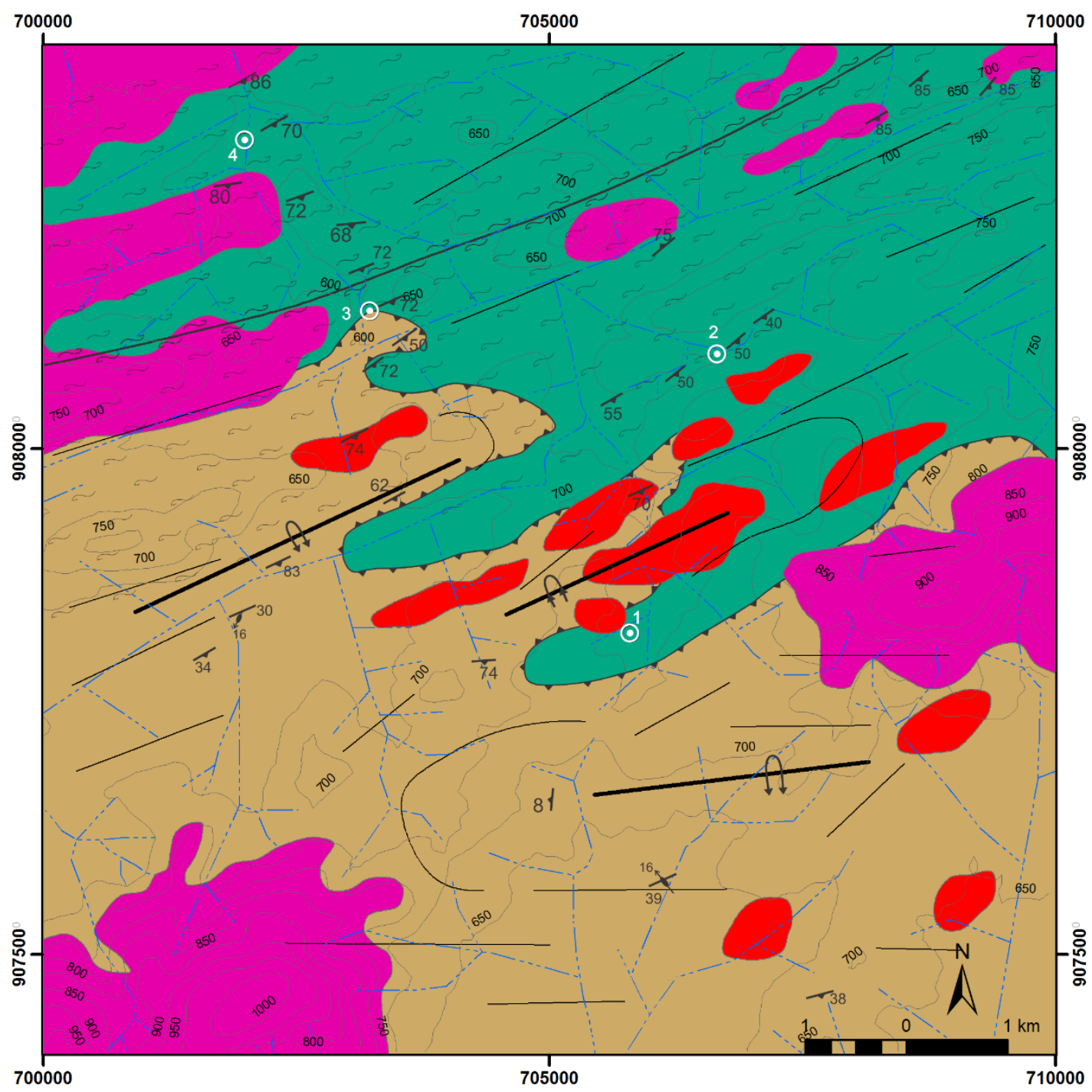

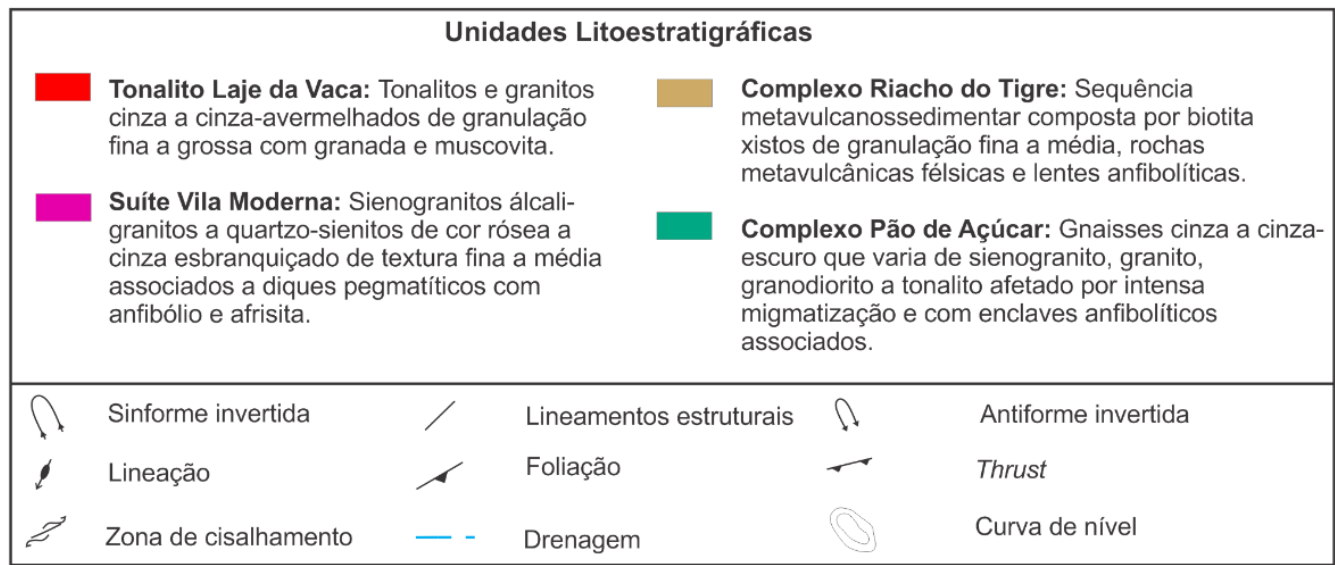

Figura 2: Mapa geológico da área de estudo. Os pontos brancos representam a localização das amostras utilizadas na análise microtectônica. Note a área afetada pela Zona de Cisalhamento Cruzeiro do Nordeste.O embasamento da área é representado pelo Complexo Pão de Açúcar (1.97 Ga; Santos, 2017). Caracteriza-se por gnaisses com quartzo, plagioclásio, feldspato potássico, anfibólio e biotita com epidoto, minerais opacos, titanita, allanita, zircão e apatita subordinadamente. A unidade é marcada pela presença de boudins de anfibolitos, localmente epidotizados, e com extensa migmatização cuja intensidade aumenta na proximidade à zona de cisalhamento e associação com sills oriundos da Suíte Vila Moderna (Fig. 2,3). 


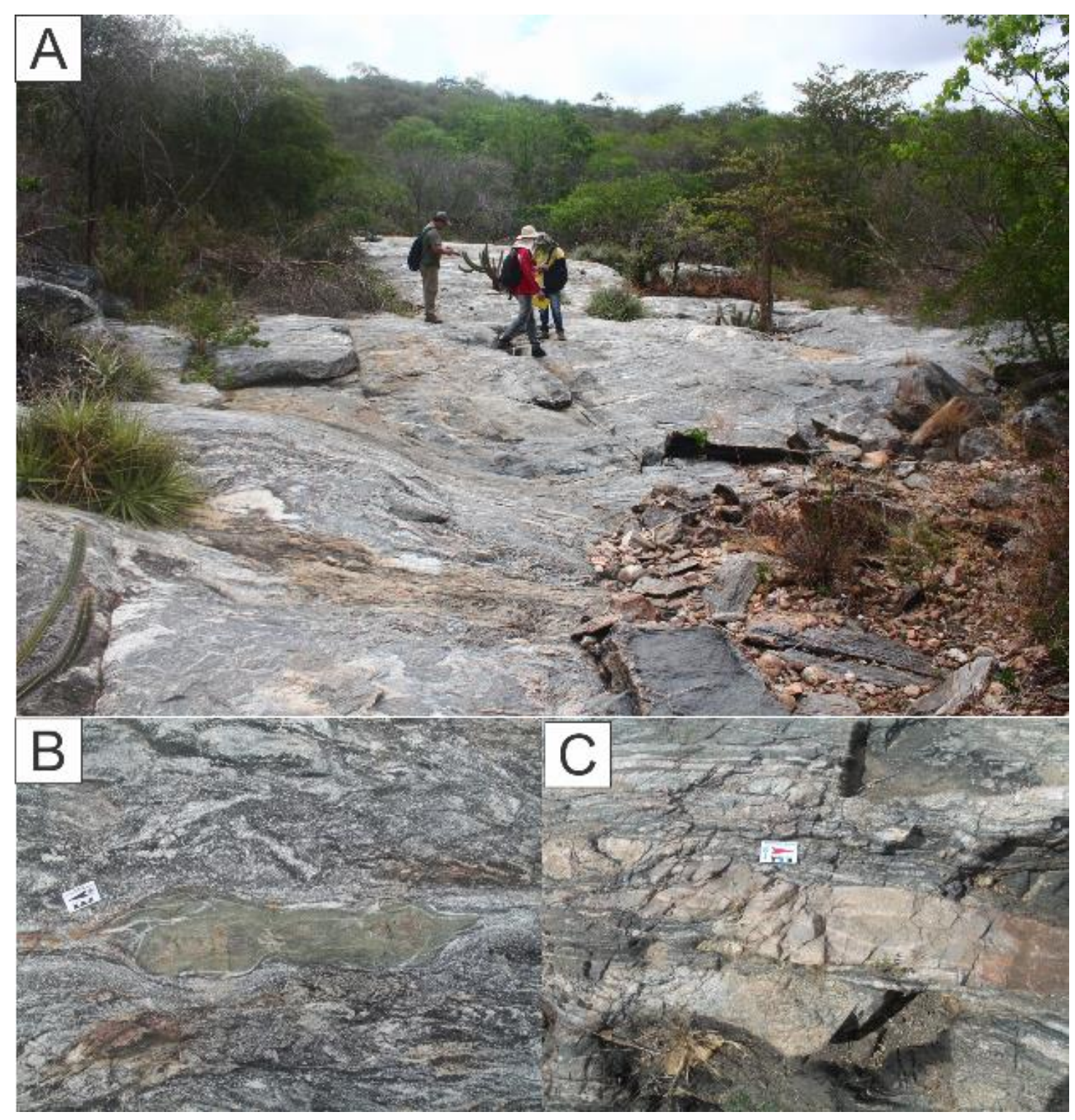

Figura 3: Aspectos de campo do Complexo Pão de Açúcar. (A) gnaisses cinza com processos de migmatização visíveis em escala de afloramento; (B) presença de boudins anfibolíticos, parcialmente epidotizados; (C) sills de textura aplítica oriundos da Suíte Vila Moderna.

O Complexo Pão de Açúcar possui contato tectônico com a sequência de rochas supracrustais do Complexo Riacho do Tigre $(0,96 \mathrm{Ga}$; Brito Neves et al., 2013; Santos, 2017). Essa unidade representa uma sequência metavulcanossedimentar com raras lentes de anfibolito (Fig. 4). Compreendem xistos de matriz fina a média composta por cristais alinhados de plagioclásio, quartzo, biotita e epidoto que circundam porfiroclastos de feldspato potássico e allanita que por sua vez possui coronas de epidoto, (Fig. 4). Minerais acessórios incluem titanita, zircão, anfibólio, opacos e apatita. 


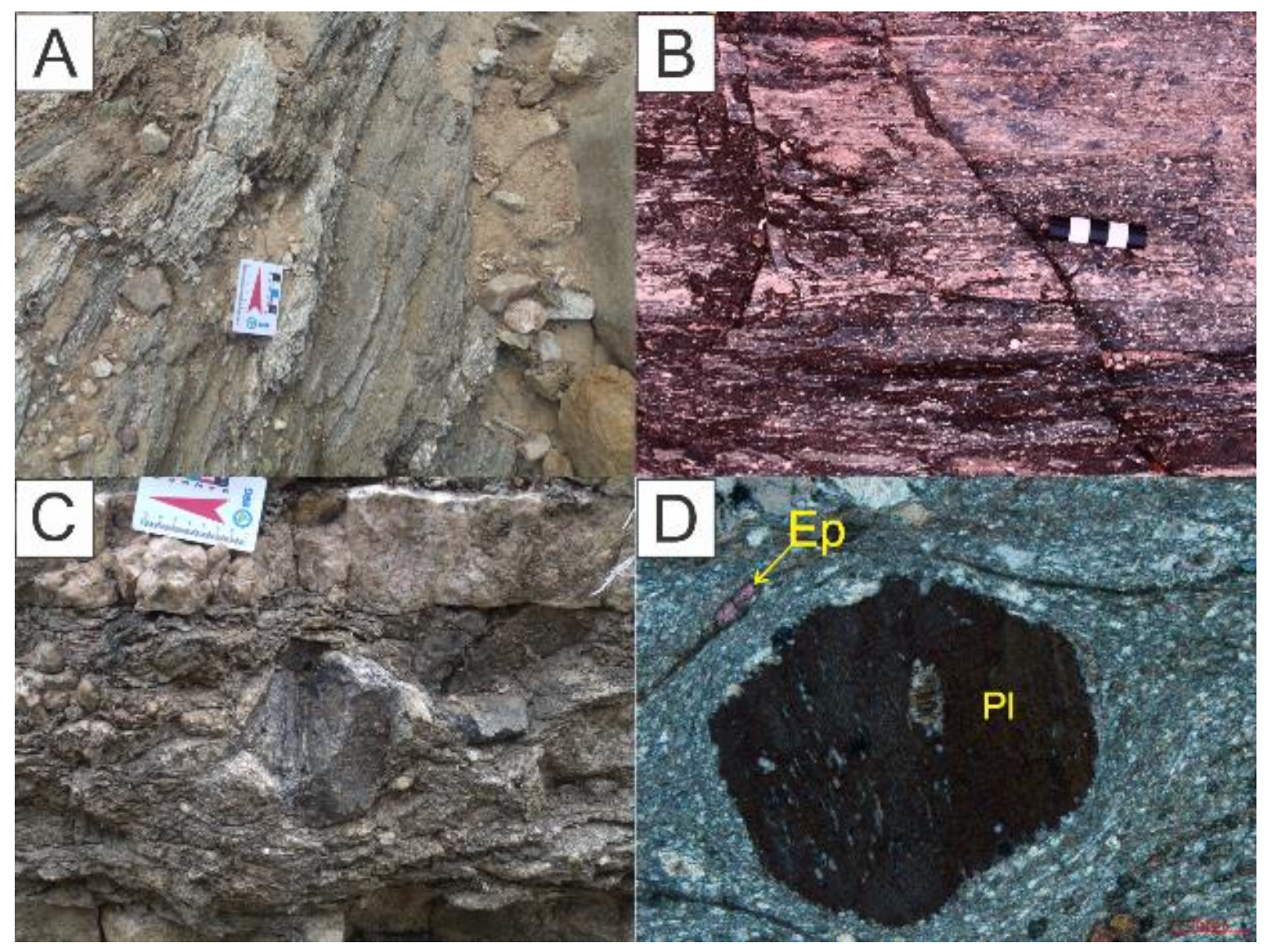

Figura 4. (A) Características marcantes das rochas do Complexo Riacho do Tigre mostrando xistos cinza com raros níveis de metavulcânicas félsicas; (B) xistos intensamente milonitizados; (C) enclaves anfibolitos de ordem centimétrica; (D) porfiroclasto de plagioclásio (PI) envolvido por uma matriz fina composta por quartzo, micas e epidoto (Ep).

$\mathrm{O}$ arcabouço estrutural da área segue $\mathrm{o}$ trend da Zona de Cisalhamento Cruzeiro do Nordeste (i.e., NE-SW). Nas porções distais à zona de cisalhamento o ângulo da foliação é de média intensidade com visível aumento nas regiões afetadas pela deformação transcorrente. Essa foliação é definida pelo plano axial de dobras intrafoliais que transpõem a foliação pretérita $S_{1}$ (i.e., $S_{2} / / S_{1}$ ) (Fig. $5 A$ ). Associado à $S_{2}$ observa-se a presença de lineação oblíqua e sigmoides assimétricos sugerindo transporte tectônico para NW (Fig. 5B). Essa feição somente foi observada no Complexo Riacho do Tigre o que permite sugerir que a unidade foi submetida a cavalgamento em direção ao Complexo Pão de Açúcar cujo contato é tectônico. Nas proximidades da Zona de Cisalhamento Cruzeiro do Nordeste de cinemática dextral a foliação torna-se verticalizada. Esse regime é indicado pela presença de sigmoides assimétricos e trama S-C definida por biotita metamórfica (Fig. $5 \mathrm{C})$. 


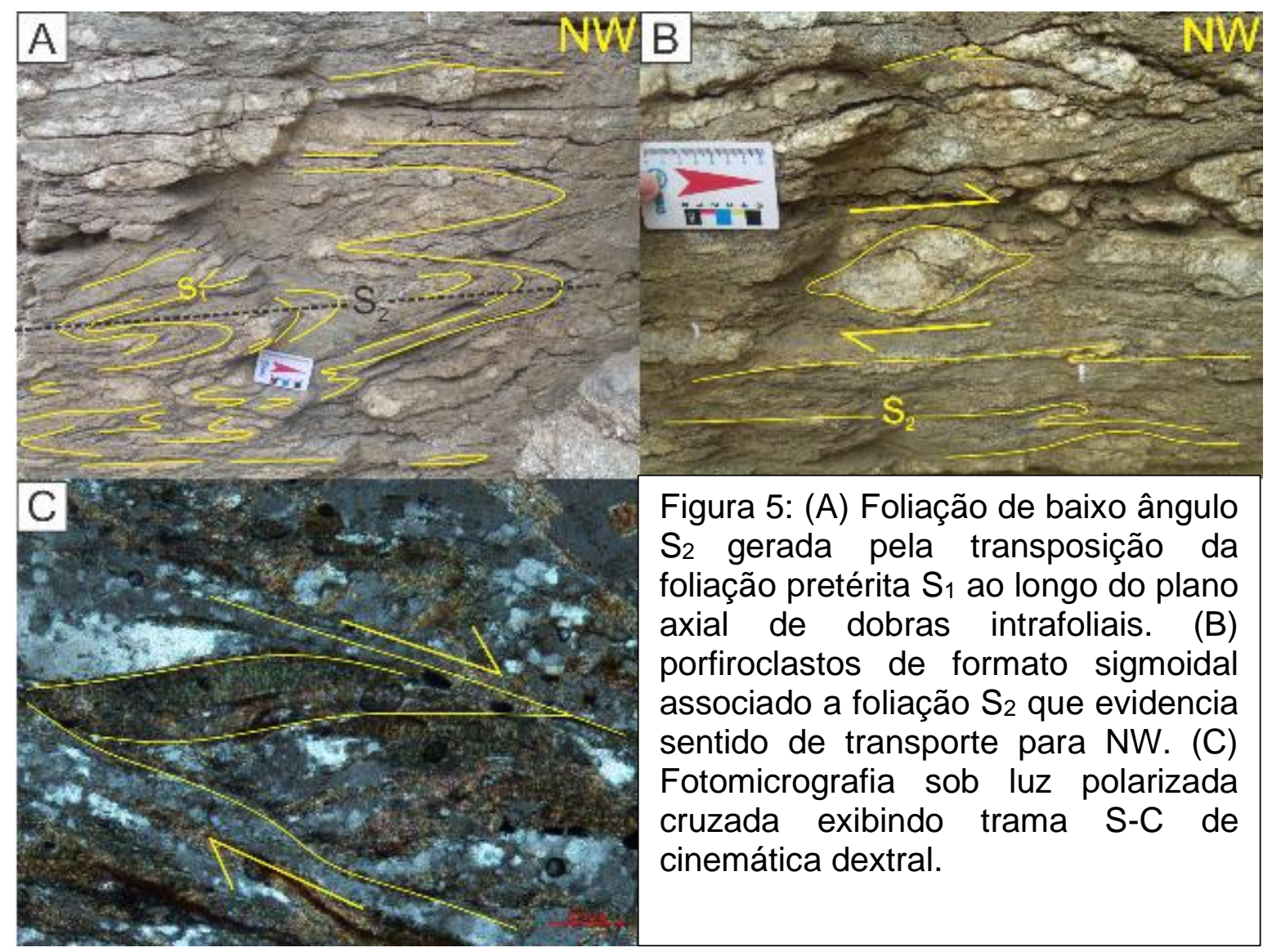

Duas suítes magmáticas intrudem as unidades mencionadas. São representadas por plutons sindeformacionais da Suíte Vila Moderna alinhados segundo a zona de cisalhamento e plutons pósdeformacionais ovalados com raros indícios de deformação do Tonalito Laje da Vaca.

A Suíte Vila Moderna é representada por quartzo-sienitos a sienogranitos, álcali-quartzo sienito e álcali-feldspato granito com aegirinaaugita e anfibólio. São rochas de cor rósea a cinza esbranquiçado e granulação fina a média. Exibem grande influência da Zona de Cisalhamento Cruzeiro do Nordeste evidenciado pela foliação milonítica caracterizada pelo alinhamento dos cristais de anfibólio e aegirina-augita além de porfiroclastos sigmoidais de feldspato potássico. Localmente podem ser observadas feições isotrópicas dessa unidade. Duas fácies principais são identificáveis com base em seus aspectos texturais de campo (SVM-I e SVM-II): SVM-I é porfirítica de composição sienogranítica caracterizada pela presença de biotita, granulação média e fenocristais de feldspato potássico com bordas de plagioclásio; SVM-II é equigranular de composição álcali-quartzo sienito a álcali-feldspato granito com granulação fina, por vezes com textura isotrópica (Fig. 6). As relações de contato com a encaixante demonstram que seu alojamento seguiu preferencialmente a foliação regional durante diversos pulsos visto que a SVM-II ocorre como sills tanto na encaixante como na SVMI (Fig. 6). 


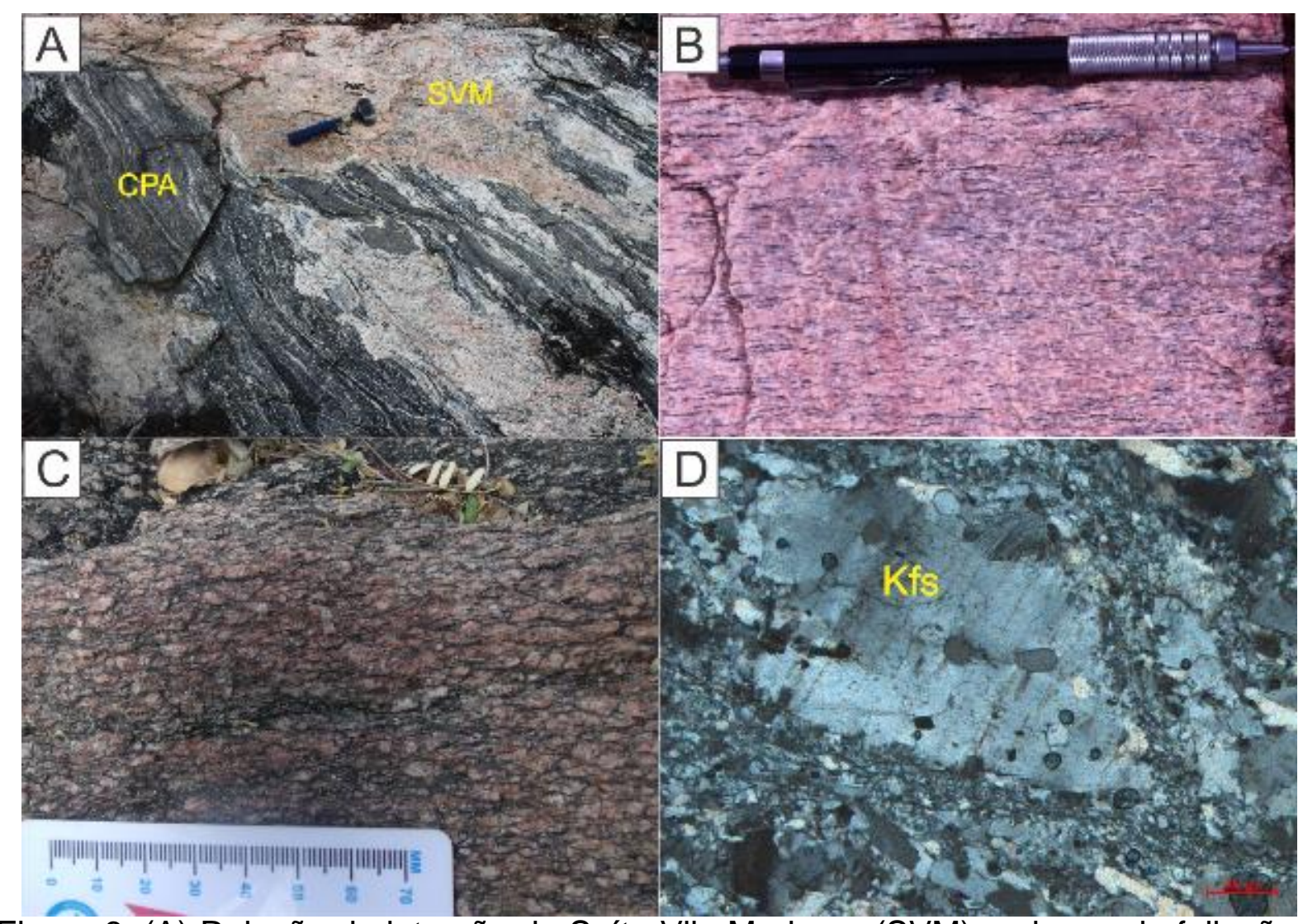

Figura 6: (A) Relação de intrusão da Suíte Vila Moderna (SVM) ao longo da foliação regional do Complexo Pão de Açúcar (CPA); (B-D) evidências de deformação em estado sólido da SVM; (B) fácies equigranular exibindo intensa milonitização; (C) fácies com porfiroclastos de feldspato potássico; (D) feldspato potássico (Kfs) exibindo intensa recristalização nas bordas.

A unidade do Tonalito Laje da Vaca (TLV) é caracterizado por rochas graníticas, principalmente de composição tonalítica de cor cinza a rósea. Destaca-se a presença de granada, muscovita, e localmente biotita, em associação aos diques pegmatíticos. As rochas desta unidade são predominantemente isotrópicas, mas localmente afetados por processos deformacionais. O TLV apresenta três fácies, TLV-I, TLV-II e TLV-III, com base nas relações de campo e textura. O TLV-I é composto por granitos e tonalitos finos de cor cinza isotrópicos a levemente deformados contendo agregados de muscovita (Figs. 7A, B). O TLV-II é composto por granitos e tonalitos com textura porfirítica, pegmatítica a aplítica de cor rósea. São caracterizados pela presença de megacristais deformados de feldspato potássico e agregados de granada (Fig. 7C, D). O TLV-III é representado por granitos finos a médios com indicações de deformação em estado sólido como maclas dobradas em plagioclásio (Figs. 7E, F). 


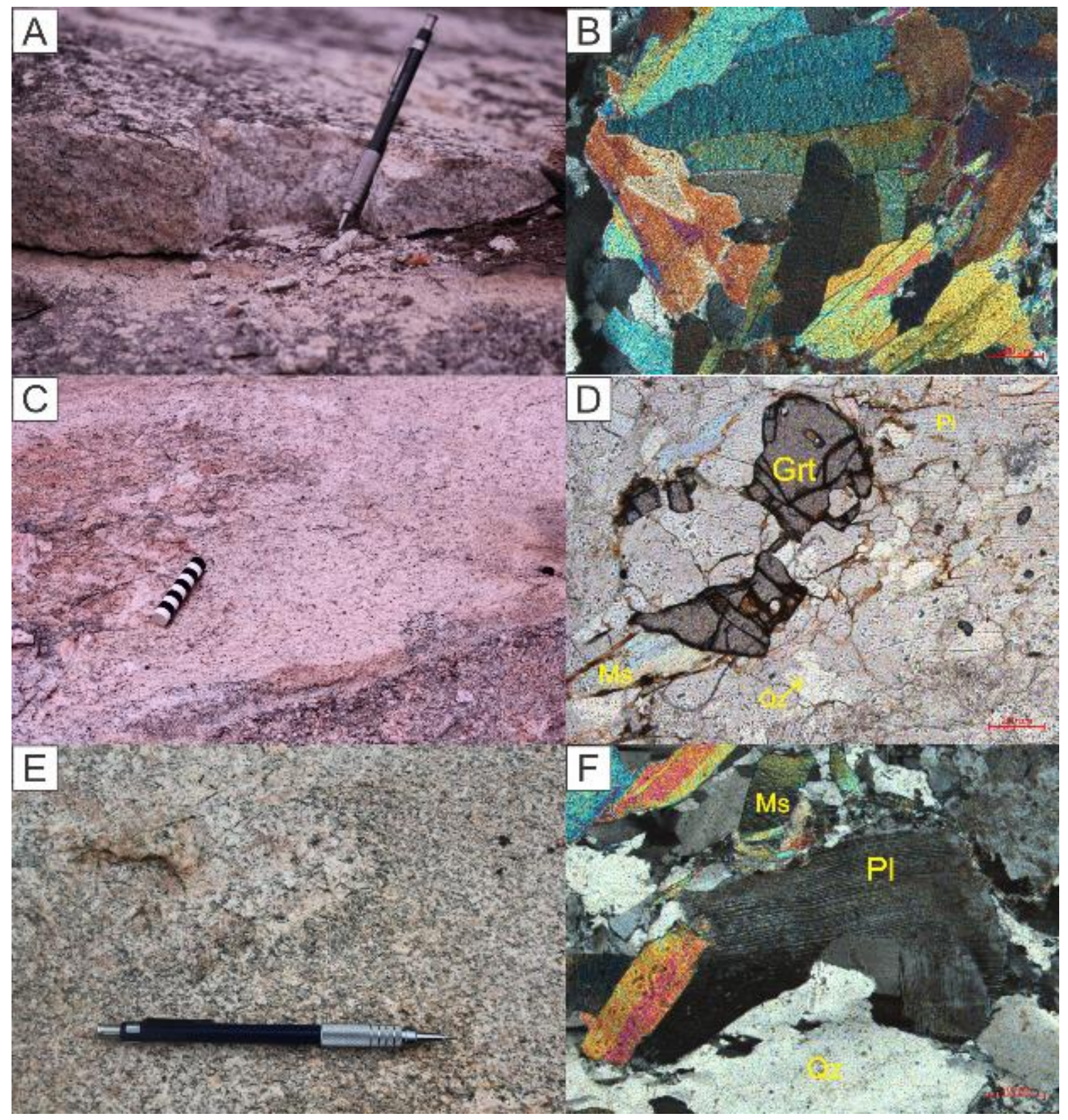

Figura 7: Aspectos petrográficos do Tonalito Lage da Vaca (TLV). (A, B) Fácies TLVI apresentando agregados de muscovita (B); (C, D) Fácies TLV-II com granada (Grt); (E, F) Fácies equigranulares (TLV-III) com indícios de deformação dúctil atestada por maclas dobradas de plagioclásio e a extinção levemente ondulante da muscovita (Ms) (Pl; F).

\section{RESULTADOS}

\section{Migmatização}

Os processos de formação de migmatitos são comumente atribuídos a um aumento de temperatura, (geralmente acima da linha de solvus de fusão granítica na presença de fluidos, isto é, $>650^{\circ} \mathrm{C}$ dependendo da pressão). Porém, sua formação está sujeita a outros fatores como $\mathrm{X}_{\mathrm{H} 2 \mathrm{O}}$ no fluido, deformação e protólito que devem ser levados em conta ao estimar a temperatura (Johannes, 1988; Sawyer, 2008).

Devido à falta de uma paragênese diagnóstica das condições P-T ocorridas, as estruturas formadas 
durante a migmatização são importantes na identificação dos eventos de aumento na temperatura associados com a zona de cisalhamento e sua relação com corpos ígneos da região.

Os processos de migmatização, registrados apenas no CPA, exibem um claro aumento de intensidade com a aproximação da Zona de Cisalhamento Cruzeiro do Nordeste, com leucossoma de composição tonalítica, sem a presença de micas, enquanto 0 melanossoma é diorítico.

O início do processo de anatexia é de caráter pré- a sin-transcorrente no qual exibe estruturas estromáticas dobradas associadas a uma elevada taxa de deformação contemporânea ao estágio de encurtamento crustal, durante o transporte tectônico para NW (i.e., $D_{2}$; Fig. 7, 8).

O segundo evento anatético é associado à acomodação lateral por escape tectônico após o forte evento compressional gerador da deformação transcorrente $\left(D_{3}\right)$. O aumento da fração de melt, associado à intensa migração do material neoformado resultaram em bolsões de leucossoma com formato sigmoidal e enclaves anfibolíticos envoltos pelo leucossoma em estrutura schollen, que sugerem uma diminuição da deformação sinanatética (Fig. 8, 9).

Por fim, o terceiro evento anatético é associado a uma baixa fração de melt e deformação sinanatética (possivelmente pósdeformacional) de caráter local que é caracterizado pela presença de texturas como patch e em rede (Fig. 8, 9).

\section{Análise microtectônica}

Para essa análise foram utilizadas quatro amostras representativas do Complexo Pão de Açúcar distribuídas conforme sua relação com a zona de cisalhamento para verificar possíveis mudanças de temperatura.

Observa-se claramente 0 aumento de temperatura refletido por mudanças texturais à medida em que se aproxima da zona de cisalhamento. $\mathrm{Na}$ amostra 1, predomina rotação de subgrão em quartzo, com incipiente recristalização pela migração de limite de grão (Fig. 8). Nos feldspatos predominam processos rúpteis, como fraturas. Entretanto, indícios de leve deformação intracristalina como extinção ondulante e maclas levemente dobradas estão presentes. Essas feições sugerem que a deformação ocorreu numa faixa de temperatura entre 450 e $500^{\circ} \mathrm{C}$.

A amostra 2 exibe mudanças texturais significativas. No quartzo o processo de recristalização predominante registrado ainda é por rotação de subgrão. Entretanto, migração de limite de grão torna-se um processo importante, sendo observado de forma disseminada. Os feldspatos ainda preservam microfraturas (provavelmente gerada antes do pico termal) e apresentam predominantemente extinção ondulante. No feldspato potássico localmente ocorre pertita 'em chamas' e mirmequita (Fig. 8) associadas aos agregados microcristalinos gerados por processos de rotação de subgrão ao redor de porfiroclastos, definindo textura mantonúcleo. A intensa recristalização do quartzo e a presença de mirmequita sugerem temperaturas durante a deformação entre $\sim 500-550^{\circ} \mathrm{C}$.

A amostra 3 já exibe indícios da influência da zona de cisalhamento. $\mathrm{O}$ feldspato exibe recristalização predominantemente por rotação de subgrão com a textura característica manto-núcleo (Fig. 8) geralmente associada a mirmequita e pertita 'em chamas'. Os processos de recristalização do quartzo são por rotação de subgrão e migração de 
limite de grão, cujas feições sugerem um intervalo de temperatura entre 550 e $600^{\circ} \mathrm{C}$ durante a deformação.

Finalmente, na amostra 4 os processos de recristalização predominantes são determinados por exsoluções em feldspato e fitas estreitas de quartzo com incipiente recristalização estática por redução de área de grão (Fig. 8). A característica predominante é a presença de quartzo com contatos irregulares gerados por migração de limite de grão, por vezes ocorrem fitas de quartzo geradas por redução de área de grão. Nessa fase a mirmequita torna-se a feição predominante no feldspato com pertita 'em chamas' localmente. Há ainda a presença de extinção ondulante e maclas dobradas no feldspato. As feições supramencionadas sugerem intervalo de temperatura durante a deformação entre $600-700^{\circ} \mathrm{C}$.

\section{Condições P-T da migmatização}

Em ortognaisses, as principais reações de melting envolvem apenas feldspatos a partir de processos de troca catiônica $\mathrm{KNa}_{-1}$, se considerarmos o sistema $\mathrm{KNASH}$, ou reações em rede ou troca envolvendo CaAINa-1Si-1 no sistema CKNASH (Spear, 1993). O diagrama da Figura 9 mostra o início da migmatização em pelo menos $650{ }^{\circ} \mathrm{C}$. A pressão mínima pode ser definida em $\sim 0.7 \mathrm{GPa}$ pela presença de zoisita como coronas em allanita enquanto a ausência de margarita e cianita pode indicar pressões máximas $<1.0 \mathrm{GPa}$ segundo curvas experimentais da relação desses minerais no sistema $\mathrm{CASH}$ (Chatterjee, 1976) e considerando que a composição química média dessas rochas (granodiorito) como sendo parte de um subsistema dos pelitos (Spear, 1993). Deve-se notar que em todas as reações a principal troca catiônica envolveu a molécula de grossulária na forma iônica $\left(\mathrm{Ca}_{3} \mathrm{Al}_{2} \mathrm{Si}_{3}{ }^{+}\right)$. O que poderia explicar a transformação parcial de lentes de anfibolitos em minerais do grupo do epidoto associado a estrutura em schollen.

O aumento da fração de melt associado $\mathrm{a}_{3}$ observado em campo é consistente com o aumento do volume e proporção de melt exibido na Figura 8. Esse aumento pode ser atribuído à diminuição da pressão para temperaturas em torno de $750^{\circ} \mathrm{C}$. 


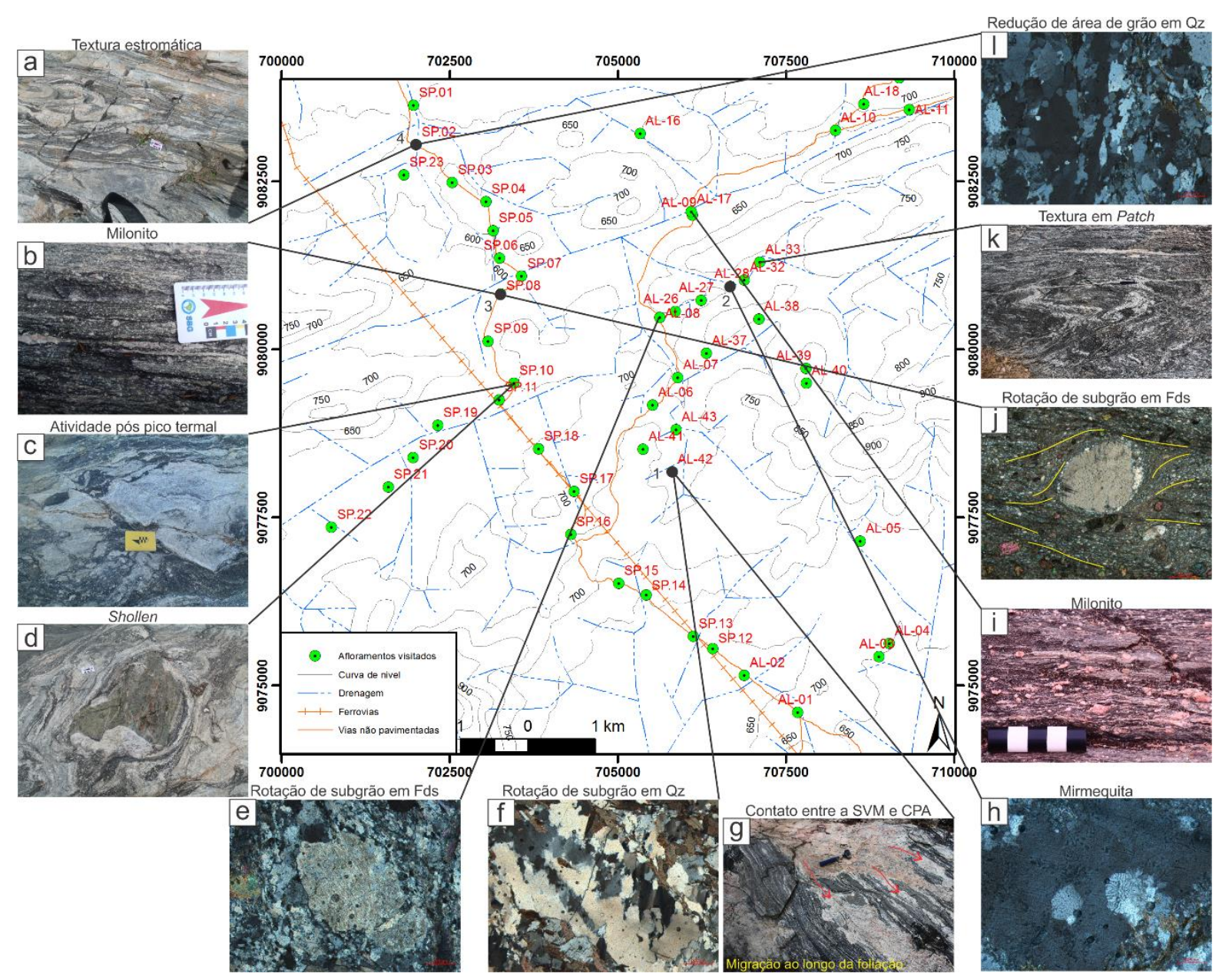

Figura 8: As principais características observadas no Complexo Pão de Açúcar (CPA) e sua relação espacial. Pontos verdes representa os afloramentos visitados, já os pontos pretos representam a localização das amostras utilizadas para o estudo microtectônico. (a) Estruturas estromáticas associadas a foliação $S_{2}$. (b) Foliação milonítica $S_{3}$ sobreposta a foliação $S_{2}$. (c) Bolsão de leucossoma associado a $S_{3}$ afetado por deformação transcorrente tardia representada por falhas sintéticas dextrais. (d) Lente anfibolítica parcialmente transformada em minerais do grupo do epidoto envolta por leucossoma em textura Schollen. (e) Porfiroclastos de feldspato circundado por grãos menores gerado por rotação de subgrão. (f) Quartzo recristalizado por rotação de subgrão. (g) Alojamento da Suíte Vila Moderna (SVM) ao longo da foliação do Complexo Pão de Açúcar com claros indícios de migração ao longo da foliação. (h) Textura mirmequita. (i) Porfiroclastos de feldspato potássico intensamente alongados devido a deformação transcorrente dextral. (j) Textura manto-núcleo em feldspato gerada por intensa recristalização por rotação de subgrão. (k) Pequenos bolsões de leucossoma em textura patch gerados após a deformação regional. (I) Fitas de quartzo geradas por recristalização estática pós deformação principal.

\section{DISCUSSÃO}

\section{Ligações entre deformação, migma- tização e plutonismo}

As características previamente descritas sugerem um história tectono- termal complexa que reforçam a íntima relação entre a colocação de plutons e o desenvolvimento da Zona de Cisalhamento Cruzeiro do Nordeste. Essas características ainda evidenciam que $\mathrm{o}$ alojamento de plutons e 
formação de zonas de cisalhamento possuem importante papel na geração de eventos de anatexia.

Os dados apresentados mostram que o pico termal não foi uniforme ou síncrono. Possivelmente teve início ainda durante a fase de encurtamento crustal; associado aos primeiros pulsos magmáticos da SVM, localizados na porção norte da área, devido a presença de estruturas estromáticas em proximidade espacial a corpos intensamente deformados da SVM (Fig. 8).

A transição do regime contracional para o transcorrente, de maneira geral, marca o pico termal no restante da área pela presença de bolsões de leucossoma envolvendo lentes anfibolíticas em textura schollen e a intensa recristalização de feldspatos em milonitos (Fig. 8). Essa transição pode ser atribuída a um processo de escape lateral após uma convergência oblíqua (e.g., Lyberis \& Manby, 1999; Konopásek et al., 2005) o qual pode ser atribuído a uma possível acomodação lateral da deformação após forte convergência (e.g., Passarelli et al., 2010; Kuiper et al., 2011).

Entretanto a presença de bolsões de leucossoma ao longo da foliação e textura schollen em formato sigmoidal sugerem que a deformação sinanatética foi de intensidade baixa a média (Fig. 9). Ou seja, a deformação durante fase de transcorrência $\left(D_{3}\right)$ permitiu $o$ transporte e eventual acúmulo do melt resultante sem tê-lo afetado intensamente. $O$ que contradiz com uma possível acomodação lateral de esforços, pois seria plausível esperar que altas frações de melt associado a elevada deformação sinanatética canalizaria o melt ao longo da foliação 0 que geraria texturas estromáticas a schliren.

Portanto, podemos inferir que a presença de melt facilitou a geração do escape lateral, como notado em análises experimentais (Grujic \& Mancktelow, 1998). Nesses experimentos notou-se que a presença de pacotes de melt facilitaria a formação de zonas de cisalhamento em padrão anastomosado o que corrobora a interpretação feita por Neves et al. (2018) a partir de dados aeromagnéticos e relações de campo. Entretanto, certas regiões afetadas pelo cisalhamento não exibem indícios de formação de melt (Fig. 9). Nesse caso propomos que o aumento regional da temperatura durante os eventos de migmatização pode ter favorecido a recristalização do feldspato enfraquecendo reologicamente a unidade permitindo a propagação da deformação transcorrente (Tullis \& Yund, 1985).

A fonte termal desencadeadora do metamorfismo foi possivelmente os plútons da SVM, tanto pela proximidade espacial quanto pelo seu caráter cedoa tardi-tectônico. Podemos ainda especular que os eventos de anatexia foram catalizados pela liberação de fluidos durante os diversos pulsos magmáticos da SVM. Seu alojamento possivelmente foi em níveis crustais intermediários durante o espessamento crustal em $\mathrm{D}_{2}$ ao longo da foliação regional similar ao alojamento de plutons sin-tectônicos no orógeno dos Pirineus em que exibem uma relação direta entre a tectônica transpressiva no alojamento de corpos ígneos e a anatexia das rochas metassedimentares encaixantes (Druguet \& Hutton, 1998).

Apesar da SVM exibir uma relação direta com a Zona de Cisalhamento Cruzeiro do Nordeste, aparentemente essa estrutura não foi o principal conduto para seu alojamento, o que é suportado pela presença de corpos relativamente distantes da zona de cisalhamento $(\sim 10 \mathrm{~km}$; Fig. 2) associado a processos de anatexia da encaixante (Fig. 9). O que sugere a 
presença de um corpo maior (não aflorante) que possivelmente alimentou esses corpos, hoje presentes em superfície. O processo de diferenciação desse corpo foi responsável pelos diversos pulsos de magma e liberação de fluidos para catalisar a migmatização; evidenciado por estarem milonitizados, por vezes isotrópicos e por intrudirem tanto pulsos anteriores quanto o embasamento.

Portanto, pode-se especular que o corpo que serviu de alimento para os corpos da SVM, e a anomalia termal por ele provocado, não só gerou anatexia do CPA mas também poderia fundir parcialmente níveis crustais mais profundos dos metassedimentos do Complexo Riacho do Tigre (CRT). Portanto, o Tonalito Laje da Vaca poderia ser o reflexo desse evento de anatexia do CRT, reforçado pelo caráter peraluminoso refletido na presença de muscovita e granada.

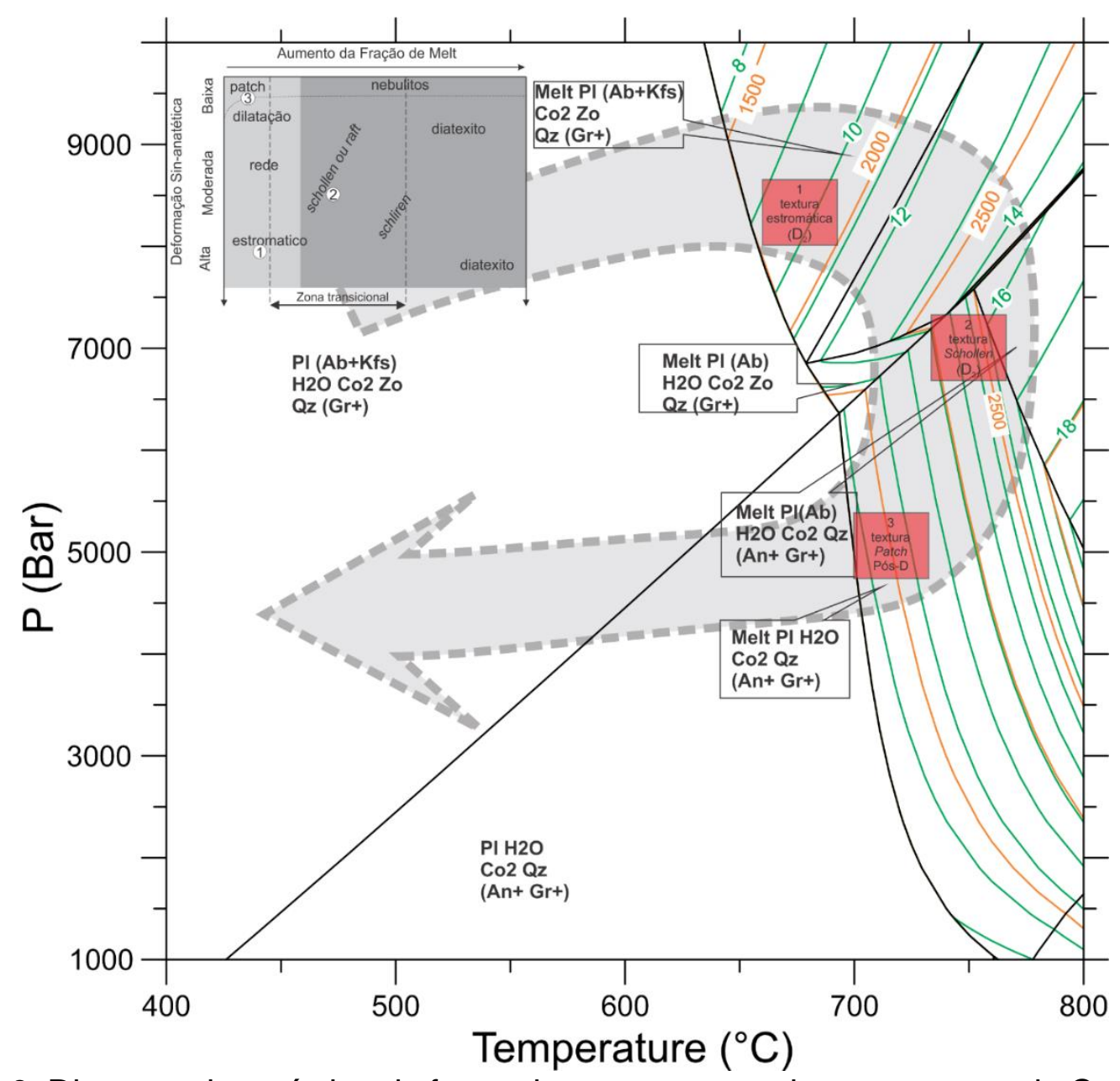

Figura 9: Diagrama isoquímico de fases de uma amostra do mesossoma do Complexo Pão de Açúcar com o campo das principais fases minerais presentes. A linha sólida verde representa a porcentagem de fusão parcial enquanto a linha sólida laranja representa o volume em $\mathrm{cm}^{3}$ de melt gerado. Os quadros em vermelho referem-se a possível sequência de formação das texturas de migmatitos e os números fazem referência ao diagrama esquemático na porção superior esquerda que relaciona a fração de melt com a deformação sin-anatética (modificado de Sawyer, 2008). Seta tracejada em cinza representa a possível trajetória interpretada para a evolução da amostra (detalhes no texto). Pl plagioclásio; Qz quartzo; An anortita; Gr granada; Ab albita; Kfs feldspato potássico; Zo zoisita. 


\section{CONCLUSÕES}

Nesta contribuição, aspectos de campo, análise microtectônica e modelamento termodinâmico mostraram a íntima relação entre a formação de zonas de cisalhamento, plutonismo e anatexia. No limite entre os Terrenos Rio Capibaribe e Alto Moxotó a Zona de Cisalhamento Cruzeiro do Nordeste foi formada possivelmente após um intenso evento de encurtamento crustal durante um transporte tectônico para NW. Essa fase é associada a geração de uma anomalia termal devido a intrusão de plutons da Suíte Vila Moderna que gerou a formação inicial de anatexia do Complexo Pão de Açúcar sob condições P-T de $\sim 0.9 \mathrm{GPa}$ e $\sim 650^{\circ} \mathrm{C}$.

A trama transcorrente dextral exibida pela zona de cisalhamento originou-se pelo escape lateral durante a convergência devido ao enfraquecimento reológico gerado pela presença de melts. Por fim, especulase que a anomalia termal na região foi causada pela presença de um corpo magmático que serviu de alimento durante o alojamento da Suíte Vila Moderna e que os níveis crustais inferiores da sequência metavulcanossedimentar do Complexo Riacho do Tigre sofreram anatexia para formação de plútons pós-tectônicos do Tonalito Laje da Vaca.

\section{Agradecimentos}

Os autores agradecem os importantes comentários e melhorias do Prof. Sérgio Pacheco Neves que revisou este manuscrito. $O$ apoio financeiro foi através do CNPq, Processo: 458735/2014-0.

\section{REFERÊNCIAS}

Accioly, A.C.A.; Oliveira, R.G.; Santos, C.A.; Leite, P.R.B.; Lins, C.A.C.; Santos, R.B.; Mendes, V.A.;
Bezerril, D.R.S. 2015. Geologia e recursos minerais da Folha Pesqueira SC.24-X-B-II. Escala 1:100.000. Estados de Pernambuco e Paraíba. Recife: CPRM - Serviço Geológico do Brasil, $154 \mathrm{p}$.

Archanjo, C.J.; Hollanda, M.H.B.M.; Rodrigues, S.W.O.; Neves, B.B.B; Armstrong, R. 2008. Fabrics of pre- and syntectonic granite plutons and chronology of shear zones in the Eastern Borborema Province, NE Brazil. Journal of Structural Geology, v. 30, p. 310-326.

Brito Neves, B.B.; Sprosser, W. M.; Petronilho, L.A.; Souza, S.L. 2013. Contribuição à geologia $e$ a geocronologia do Terreno Rio Capibaribe (TRC, Província Borborema). Revista do Instituto de Geosciências - USP, v. 13, p. 97-122.

Chatterjee, N.D. 1976. Margarite stability and compatibility relations in the system $\mathrm{CaO}$ $\mathrm{Al}_{2} \mathrm{O}_{3}-\mathrm{SiO}_{2}-\mathrm{H}_{2} \mathrm{O}$ as a pressuretemperature indicator. American Mineralogist, v. 61, p. 699-709.

de Capitani, C. \& Brown, T.H. 1987. The computation of chemical equilibrium in complex systems containing non-ideal solutions. Geochimica Cosmochimica Acta, v. 51, p. 2639-2652.

Druguet, E. \& Hutton, D.H.W. 1998. Syntectonic anatexis and magmatism in a mid-crustal transpressional shear zone: an example from the Hercynian rocks of the eastern Pyrenees. Journal of Structural Geology, v. 20, n. 7, p. 905-916.

Grujic, D. \& Mancktelow, N.S. 1998. Melt-bearing shear zones: analogue experiments and comparison with examples from southern Madagascar. Journal of 
Structural Geology, v. 20, n. 6, p. 673-680.

Hirth, G. \& Tullis, J. 1992. Dislocation creep regimes in quartz aggregates. Journal of Structural Geology, v. 14, p. 145-159.

Holland, T.J.B. \& Powell, R. 2011. An improved and extended internally consistent thermodynamic dataset for phases of petrological interest, involving a new equation of state for solids. Journal of Metamorphic Geology, v. 29, p. 333-383.

Hunter, N.J.R.; Hasalová, P.; Weinberg, R.F.; Wilson, C.J.L. 2016. Fabric controls on strain accommodation in naturally deformed mylonites: The influence of interconnected micaceous layers. Journal of Structural Geology, v. 83, p. 180193.

Hunter, N.J.R.; Weinberg, R.F.; Wilson, C.J.L.; Luzin, V.; Misrz, S. 2019. Quartz deformations across interlayered monomineralic and polymineralic rocks: A comparative analysis. Journal of Structural Geology, v. 119, p 118-134.

Johannes, W. 1988. What controls partial melting in migmatites? Journal of Metamorphic Geology, v. 6, p. 451-465.

Konopásek, J.; Kroner, S.; Kitt, S.L.; Passchier, C.W.; Kroner, A. 2005. Oblique collision and evolution of large-scale transcurrent shear zones in the Kaoko belt, NW Namíbia. Precambriam Research, v. 136, n. 2, p. 139-157.

Kuiper, Y. D.; Lin, S.; Bohm, C.O. 2011. Himalayan-type escape tectonics along the Superior Boundary Zone in Manitoba Canada. v. 187 n. 3-4, p. 248262.
Lyberis, N. \& Manby, G. 1999. Continental collision and lateral escape deformation in the lower and upper crust: An example from Caledonide Svalbard. Tectonics, v. 18, n. 1, p'. 40-63. Miranda, T.S.; Neves, S.P.; Celestino, M.A.L.; Roberts, N.M.W. 2020. Structural evolution of the Cruzeiro do Nordeste shear zone (NE Brazil): Brasiliano-PanAfrican-ductile-to-brittle transition and Cretaceous brittle reactivation. Journal of Structural Geology, 141, 104203.

Neves, S.P. 2015. Constraints from zircon geochronology on the tectonic evolution of the Borborema Province (NE Brazil): Widespread intracontinental Neoproterozoic reworking of a Paleoproterozoic accretionary orogen. Journal of South American Earth Sciences, v. 58, p. 150-164.

Neves, S.P.; Santos, T.A.S.; Medeiros, C.M.; Amorim, L.Q.; Casimiro, D.C.G. 2018. Interference fold patterns in regional unidirectional stress fields: A result of local kinematic interactions. Journal of Structural Geology, v. 115, p 304-310.

Neves, S.P.; Vauchez, A.; Archanjo, C.J. 1996. Shear zone-controlled magma emplacement or magma-assisted nucleation of shear zones? Insights from northeast Brazil. Tectonophysics, v. 262, p. 349364.

Passarelli, C.R.; Basei, M.A.S.; Wemmer, K.; Siga Jr., O.; Oyhantçabal, P. 2011. Major shear zones of southern Brazil and Uruguay: escape tectonics in the eastern border of Rio de La Plata and Paranapanema cratons during Western 
Gondwana amalgamation. V. 100, p. 391-414.

Passchier, C.W. \& Trouw, R.A.J. 2005. Microtectonics, 2ed. Springer, Berlin.

Platt, J.P.; Behr, W.M. 2011. Grainsize evolution in ductile shear zones: Implications for strain localization and the strength of the lithosphere. Journal of Structural Geology, v. 33, p. 537-550.

Santos, C.A. 2017. Geologia e recursos minerais da folha Sertânia SC.24-X-B-I: estados de Pernambuco e Paraíba. Recife, CPRM. 158p.

Sawyer, E. W. 2008. Atlas of Migmatites. The Canadian
Mineralogist, Special Publication 9. NRC Research Press, Ottawa, Ontario, Canada. $371 \mathrm{p}$.

Spear, F.S. 1993. Metamorphic phase equilibria and pressuretemperature-time paths. Mineralogical Society of America, Monograph, 799 p.

Van Schmus, W.R.; Kozuch, M.; Brito Neves, B.B. 2011. Precambrian history of the Zona Transversal of the Borborema Province, NE Brazil: Insights from Sm-Nd and $\mathrm{U}-\mathrm{Pb}$ geochronology. Journal of South American Earth Sciences, v. 31, p. 227-252. 